Vol 4 Number 2

ISSN: 2407-0742

\title{
A PRAGMATICS ANALYSIS OF SPEECH ACT IN THOR MOVIE
}

\author{
Tri Lestari ${ }^{1}$, Elysa Hartati ${ }^{2}$ \\ English Education Department, Faculty of Teacher Training and Education \\ Mercu Buana University of Yogyakarta \\ $\underline{{ }^{1} \text { trilestari.umby13@gmail.com, }}{ }^{2}$ hartatielysa@gmail.com
}

\begin{abstract}
This research analyzed speech act which were expressed by Thor as the main character in Thor movie. That movie showed a candidate of king who was banished by his father because of his arrogant characteristic, so, there were many speech act which represented real life. Considering there are problems in English language learning focusing on speech act, so this study was conducted used pragmatics analysis. The purposes of this study were to classify speech act based on Searle's theory and analyze speech act which has relation between the form and the function of the sentence.This research used descriptive qualitative method. The data which were used in this research were the utterances that were performed by the main character in the movie. The data analysis used pragmatics approach with theory by Searle. From the theory, there are 5 classifications of speech act, representative, directive, commissive, expressive, and declarative. There are 2 types of speech act which is discussed by Searle, direct and indirect.Based on the analysis, the researcher found that from the 5 classifications only 4 of them which were expressed by the main character, representative, directive, commissive, and expressive. Representative and directive were expressed 56 times each of them. Commissive appeared 20 times and expressive appeared 29 times. All types of speech act were expressed by the main character in the movie. Direct speech act were expressed 140 times, and indirect speech act were expressed 11 times.
\end{abstract}

Keywords: pragmatic, speech act, Thor movie

\section{A. INTRODUCTION}

Language is a tool of communication which is used by all people in the world which is applied by two people as minimum. Language is the most important tool for human being because it has significant function for every individual. It is used to deliver message, convey information or even just to talk to others. Language is not only used in one form but there are three forms of language which usually used by the people: spoken, written or sign. Both human and animal have communication for their interaction in daily life. Those creatures communicate in the same way which mean for sharing information. Although in 
the same way, animal do not have language like human. Animal only use their gesture and sound to communicate with other animals in present time while human have language which is used in three period of times; past, present, and future. Human language is also more complex because it has displacement, arbitrariness, productivity, cultural transmission, and duality (Yule, 2010:11). Animal do not have language because till now there is no research which found that animal can speak using language like human (Taher, 2015). Performing language is close to doing communication although only use signs language for interaction. Communication is done by two or more individual which position as speaker and listener with a message inside of it. When doing communication, speaker and listener perform language using many utterances. That kind of utterances which is performed in English linguistics is called as speech act (Yule, 1996:47).

Griffiths (2006:148) stated that speech act is the basic unit of linguistic interactions such as giving warning, greeting, applying, telling information, confirming an appointment, and other expressions. Every expression which people talk about in daily life is example of speech act, but they do not realize that. It is clear that speech act has a big scope of language, all sentences that people speak are speech act or even the word "Hello" is one of speech act example for greeting. Hence, speech act is used every day, every time, and everywhere in this world. Speech act is the utterances which are performed in action by two people or more as a speaker and hearer (Yule, 1996:47). All sentences which appear in conversation are include in speech act as describe by Austin (1955:52) that speech act consists of both proposition statement and total situation of utterances. Speech act does not only focus on the sentence of conversation but also the situation of it because a sentence has meaning when it is related to the situation or the context. Hence, when people analyze speech act, they cannot separate among activities, situation, and conversation.

According to Huang as quoted by Mey (2009: 1002-1003), Austin classifies there are three kinds of speech act: locution, illocution, and perlocution. Locutionary act is the basic act of speaking which concerned with physical act of producing sound, constructing a good string of sign, and responsible for task. 
Illocutionary act is the act done in speaking which has purpose of something or can be called as function of the spoken language. Sadock based on Austin's (in Horn and Ward 2006:55-64) states that the characters of illocutionary act is the use of canonical by assumption. He explains acts of ordering and requesting are typically using imperative sentences, and acts of asking using interrogative sentences. One illocutionary act can make different illocutionary force because every single illocutionary act is ambiguous, it can be interpreted based on the circumstance. Sadock adds Austin classified illocutionary act become five, verdictives, exercitives, commisives, behabitives, and expositives. Perlocutionary is the act performed by illocutionary act. It is the effect of the speaking utterances of illocutionary said. It can be an action, feeling, or thought of the speaker, listener, or other parties of communication.

Cutting (2002:16-17) has different classification of illocutionary act based on Searle's (1976) solution grouping it as declaration, representative, commissive, directive, and expressive.

1. Declaration

Declaration is the expression of some words that makes the real situation around the speaker change by their utterances. Huang (in Mey 2009:1004) adds "Declarations (or declaratives) are those kinds of speech acts that effect immediate changes in some current state of affairs." It is clear that declaration makes the world change both in small or big occasions. The example of declaration when the speaker "I" state "I resign from this job", so it means that the speaker do not work again in that job.

2. Representative

Representative is the utterances which consist of word that show the speaker's believe to be the case. Huang (in Mey 2009:1004) also stated that it is kind of speech act which lead the speaker to the truth-value of something. Describing things, reporting some event, concluding an issue is the example of representative.

3. Commissive

Commissiveis the words which commit the speaker about future action can be after the utterances done or the next time. After the speaker express the 
words, she or he has to do some action related to the word. This example maybe make you understand this definition; Smith say "I promise to get two tickets of the concert" after that sentence, Smith will buy the tickets.

4. Directive

Directive is the words which have relation to other people; the people who do some actions here is the hearer. When the speaker says something, the hearer then will do some actions related to the sentence. Some utterances in restaurant are the example of this kind of speech act. It happens when the customer requesting some menu to the waiters, then they will do something to serve the customer's request.

5. Expressive

Expressive, the last classification of speech act by Searle is the group of words which express what the speaker feels in some occasions. According to Huang (in Mey 2009:1004) it shows a psychological attitude of the people who say it. These can be the expression of like, dislike, joy, and sad or in a real situation can be act of apologizing, blaming, praising, thanking, regretting, and other expression of feeling.

Speech act not only has some classification but also has some types. Huang (in Mey, 2009:1000) written that Searle has different type of speech act which has relation with illocutionary force. Meanwhile, speech act can be standalone but it also has relation with other part of sentence, so Searle related it with illocutionary force. According to Searle as quoted by Cutting (2002:19) there are two types of speech act: direct speech act and indirect speech act which will be explain in the following.

1) Direct Speech Act

Direct speech act is the expression of speaker's utterances which there is direct relationship between the form or structure of the utterance and the function of illocutionary act. This type of speech act has correlation with the classification of speech act itself which has mentioned before. Here are the examples of direct speech act according to Austin's lists in Griffiths (2006:148149). 

a. Statement : "I lived in Indonesia for six years."
b. Order : "Pay this bill as soon as possible."
c. Question : "Where is my bag?"
d. Prohibition: "Do not turn right here!"
e. Greeting : "Hello."
f. Invitation : "Help yourself."
g. Felicitation :'Happy New Year!"
h. (Grudging) apology: "I hereby apologize as required by the magistrate."

All utterances above are the example of direct speech act based on single sentence. There is no sentence before-after it and we do not know the context of that utterance. We know that an utterance (a) is the example of representatives and it is to show statement, so it is called as direct speech act. See also in utterance (c), the form of utterance is question or interrogative and it has function to express directive. Yule (1996:54) also adds that there are three structural forms of sentence: declarative, interrogative, and imperative and there are three general communicative functions: statement, question, and command/request. It is can be called as direct speech act when there is direct relationship between a structure and a function.

2) Indirect Speech Act

On the other hand, indirect speech act is the speaker's utterances of expression which the function of the illocutionary act and the form or structure of expression not directly related. Indirect speech act happen when declarative is not used as statement, interrogative is not used for question and imperative is not used for command or request. According to Griffiths (2006:149) interrogative form can be called as indirect speech act when context indicates that it is reminders or request. One utterance can be called as direct speech act and indirect speech act based on the context of the utterance. Based on Brown and Levinson (1987), indirect speech act has correlation with politeness because polite action can be done well using indirect speech act to avoid direct imposition. In requesting something, it more polite when using interrogative 
form rather than imperative form, which is in speech act it called as indirect speech act (Horn and Warn 2006: 71).

Interrogative form of sentence can be called as indirect speech act, for instance "Can you open the door?" in the situation of someone knocks the door from outside. This sentence is in the form of interrogative or question, but the function of this sentence is asking so it is called as indirect speech act. Another example from Yule (1996:55) "It's cold outside" is in the form of statement, but when it is functioning as "I hereby request of you that you close the door" becomes request and called as indirect speech act. "It's cold outside" directly can be called as indirect speech act when we know the context: we have meeting in the room without $\mathrm{AC}$ and the door is open, then someone says "It's cold outside" afterwards someone who near the door close it. So it is clear that utterance in the form of declarative has function to request.

Delivering information or expressing speech act is not always success because sometimes the speaker uses different kind of utterances which has different meaning, so the listener gets problem to understand it. The listener has to think twice before he/she gets the meaning of the message even sometimes he/she gets misunderstanding. Hence, in that case appears a problem in communication which should be solved.

As a simple utterance of speech act which becomes a problem in daily conversation, a speaker says "Can you open the window?" which means asking for request, but the listener just responds "Yes" without any action. This is one of the problems appears when both the speaker and listener do not get the same knowledge. From this example, it shows that knowledge about utterance is important to understand what actually the message of the utterance is. If everyone does not have any knowledge about linguistics and does not want to study about it, the people in this world will get confused and many problems appear in conversation.

Problem of linguistics not only happens in daily conversations but also in other parts of human such as debates, films, art performances, television programs and other interactions. Movie is one part of humans' interactions which nowadays becomes popular trend in many countries. Movies are not only shown in the 
country which produces it but also in other countries. In Indonesia, people know that many movies from foreign countries are played here and sometimes they do not really understand when watch it. When people do not understand the movie, it becomes a problem. The problem which may appear in watching movies is misunderstanding of the meaning of utterances or do not know the message of the utterances so they need to study about other languages especially on speech act.

In this world, there are many movies which used English as the language and those movies usually come from America. Movies from America are shown by many people in this world because it is the center of movies' industry. One of American movie is Thor, it is an action movie which is produced not only once. It is a famous and popular movie which is seen in many countries and has many lovers. So, when it is discussed, it will be interesting for the lovers.

Thor, the main character of the movie, has to live in the earth alone, without any friend, any home, and any powers. He does not have anything in new place but he must survive and gets his hammer again. Then, he meets Jane, Darcy, and Dr. Selvig, he tells to them about his hammer but they do not know. In this condition, there are many utterances of speech act appearing in conversation which are performed by Thor that can be analyzed using pragmatics analysis. Thor movie also has other series, so it can be useful for the next researcher who will conduct a research of next Thor movie.

In Thor movie, Thor said "This was to be my day of triumph", if it is just single utterance like that, people know that it is a declarative in a form of statement and called as direct speech act. Afterwards, it is an example of datum from the movie, when there is situational context: that day is coronation Thor becomes a king of Argard, but in the middle of ceremony, there are some adversaries infiltrate to the kingdom and destroy the company, so the ceremonial is canceled and Thor does not get his coronation because of the destroyer. After see the context, people can understand that Thor's utterance is the expression of sad or can be classified as expressive and belongs to indirect speech act because it do not directly shows the meaning of the utterance.

Another example from the movie is utterance "I've changed" when there is no context, people see it as a stating expression which in speech act classification 
belongs to representative. But when it has a context; the utterance happen when Thor, the speaker opposes Loki, who previously said "you could have killed them all with your bare throne!" in Asgard because Loki made mistake and want to kill all people. After see the context, people will know that Thor's utterance is opposing expression, not stating expression.

Utterances above are example of the utterances in the movie and sometimes appear in daily conversation. If there is no explanation like that, people do not know the classification and type of that utterance furthermore in the same case like that. It shows that movie is the representative of daily activities which is recorded to be shown in public. By this phenomenon, the researcher will conduct the research entitled: "A Pragmatics Analysis of Speech Act in Thor Movie" focusing on classification of speech act ant type of speech act itself.

\section{B. METHOD}

Creswell (2014) stated that there are three kinds of approaches on research: qualitative, quantitative and mixed. Qualitative research is an approach which focuses on human problem; it is the approach for exploring and understanding meaning of individual or the social relation of some groups. Quantitative approach is designed for group of people which testing some theories in some variables. It is the way for examining a theory suitable for the groups or not. While, mixed methods is the combination of qualitative and quantitative approach. This method usually used for complex problem which cannot be finished using qualitative approach or quantitative approach.

Based on the definition above, the researcher used qualitative research because the subject of the research was human and the outcome was narrative description of the finding. Creswell (2014: 42) says "The historic origin for qualitative research comes from anthropology, sociology, the humanities, and evaluation." The research which was conducted was kind of humanities, so based on Creswell it used qualitative method to collect the data. Although this research used qualitative method, there is some numeric data is used to make the reader easy to understand this research especially on the findings. 
The object of this study was Thor movie, the movie script was the source of data of this study, while the main character's utterances were the data of the research. The researcher chose the main character in Thor movie because he was the ones who made many utterances in some actions. The main character of the movie was Thor. The data were the combination of Thor movie script, the English subtitle and the original movie. The movie script was gotten from website www.imsdb.com, whereas the English subtitle of the movie was gotten from website https://subscene.com/, and the original movie was rented from Google play store.

The research was conducted in qualitative method which had research instrument. In this research, there were two instruments. They were the investigator and the Thor movie script. The investigator here was as the human instruments who analyze the data to get information. In doing this research, there were three investigators and all of them had the same analysis of the data. Besides, the Thor movie script was the document which becomes the data to be analyzed.As the instrument of this research, the researcher had the role of planning, collecting, analyzing, and reporting the finding of the research. The researcher used tables for identifying and analyzing the data. Then, after finish identified and analyzed, the researcher made the report by writing the description of the finding.

\section{FINDING AND DISCUSSION}

That there are five classification of speech act based on Searle: representative, directive, commissive, expressive, and declarative. Four of them were presented by the main character in Thor movie; they were representative, directive, commissive, and expressive. Declarative was not performed because it needed special event and special people who expressed it. In the movie, Thor as the main character is an ordinary person, and there was no special event so he did not express declaration.

Representative is a kind of speech acts which consists of word that show something to be the case; it is a truth which can be proof true or false. Representative was performed many times, it was divided into 9 illocutionary 
force; those forces were: affirming, agreeing, convincing, correcting, explaining, stating, stating enthusiasm, stating opinion, and telling. Each of them had difference times of frequency because the data analysis came from the real utterances from the movie. Affirming and agreeing appeared in the movie 5 times each of them. Convincing, correcting, and stating enthusiasm appeared only once each of them. Explaining appeared 13 times, while stating force appeared 19 times. Stating opinion appeared 3 times and the last force was telling appeared 8 times, so the total of representative was 56 data.

Directive is a kind of illocutionary act which involves other people in the utterance. The speaker expresses his/her utterance to other to ask the listener because in directive the one who do the action is the listener. Directive was performed in 7 illocutionary forces: calling, commanding, ordering, prohibiting, protesting, questioning, and requesting. Calling expression appeared 4 times while commanding expression appeared 13 times. Ordering appeared only 2 times and prohibiting only once. Protesting expression appeared5 times whereas questioning appeared 19 times. The last, requesting appeared 12 times, so the total data of directive was 56.

Commissive is an act which commits the speaker to do future action, it can be done both after the utterance and the next time. Commissive was performed in 5 different illocutionary forces, those were offering, opposing, planning, promising, and vowing. Each of them had different frequency of appearing, but there were 2 forces with the same frequency; offering and promising was appeared 5 times each of them. Opposing appeared 2 times whereas planning appeared 7 times. Vowing expression only appeared once, and the total data of commissive were 20 .

Expressive is classification of speech act which consists of words that shows speaker's feeling in some occasions. It is used to show physical attitude of the speaker. Expressive was the classification which expressed by the main character with the most various illocutionary forces. It had 11 different illocutionary forces, they were apologizing, demanding, grumbling, praising, regretting, responding, shocked, stating angry, stating goodbye, stating happy, and thanking. Some of them had the same frequency of appearing; apologizing and 
thanking appeared 5 times each of them. Demanding, grumbling, responding, shocked, and stating happy only appeared once, whereas regretting and stating good bye appeared 2 times each of them. Praising appeared 4 times and stating happy appeared 6 times, so the total data were 29.

There were two types of speech act which were performed by the main character. They were direct speech act and indirect speech act. There was direct speech act if the speaker expressed his/her utterances based on the normal form. Indirect speech act occurred when the speaker did not follow the normal form. In this research, there were 3 forms which made indirect speech act in this research.

Direct speech act is types of speech act which is distinguished by the made of structure with the function. There are 3 structural form of sentence (declarative, interrogative, and imperative) which has relationship with 3 general communicative functions (statement, question, and command/request). Speech act is called direct if declarative uses for statement, interrogative uses for question, and imperative uses for command/ request. There were 140 data of direct speech act which were performed by the main character. 90 data came from declarativestatement, 25 data from interrogative-question, 20 data from imperativecommand, and 5 data came from imperative-request.

Indirect speech act is speech act which is expressed not using the normal forms of structure and function. The speech act which not included in direct speech act is included in indirect speech act. In this research, there were 3 forms which made indirect speech act: declarative used for request, interrogative used for request, and interrogative used for statement. Indirect speech acts were expressed by the main character 11 times of all the data. There were 8 data from declarative-request, 2 data from interrogative-request, and 1 datum from interrogative-statement.

\section{CONCLUSION}

Based on the research findings and discussion which are explained before, there are some conclusions in this research. The first conclusion is related to the first problem: what are the classifications of speech act in Thor movie based on Searle's theory. The second conclusion is related to the second problem: what are 
the types of speech act used in Thor movie. Those conclusions actually had mentioned in the chapter four, but here are the summary of them. The summaries are detailed in the following paragraph.

There are 5 classifications of speech act which are mentioned by Searle: representative, directive, commissive, expressive, and declarative. In this research, only 4 of them were expressed by the main character in the movie. The classifications which were performed by the main character were: representative, directive, commissive, and expressive. Both representative and directive were expressed 56 times each of them, it showed that the main character expressed them mostly because he loved to express something directly and he needed to give much information to the listener. Commisive was expressed 20 times; it was the rare expression which was performed by the main character because he did not care about others, and expressive was expressed 29 times in the movie. The last classification which was not performed was declarative since it needed special event and special speaker, so it was not performed in the movie.

Mostly the people express speech using representative and directive because the speaker and the listener directly meet each other and the utterance is expressed spontaneously. It has the same thing with this result of this research; the main character did his utterances mostly in representative and directive because he directly utters it to the listener. Thor, as the main character has authority to ask his friends to do something, so he mostly did directive speech act. As the example: Thor utters "get him to healing room" which means Thor asks his friends to bring Volstagg to the healing room, so is classified as directive speech act.

Related to second problem, there are two types of speech act based on Searle: direct speech act and indirect speech act. Those two types can be differentiated based on the form of the sentence and the function of the sentence. Both of them were expressed by the main character in the movie, but one of them had many frequency of appear. Direct speech act was the most types which were expressed by the main character; it was expressed 140 times, while indirect speech act was only expressed 11 times. The main character mostly expressed his utterances directly because it is the easy way to communicate with the listener. Direct speech act easier to be expressed and to be understood by the listener. 
While indirect speech act is used to express something in polite such as asking for something using interrogative form which was expressed bu the main character in this movie.

There were 4 forms which made direct speech act, and 3 forms which made indirect speech act. The forms of direct speech act were declarativestatement, interrogative-questions, imperative-command, and imperative request. Indirect speech act was made by forms of declarative-request, interrogativerequest, and imperative-statement.

\section{REFERENCES}

Austin. 1955. How to Do Things With Words. Oxford: Oxford university press Creswell, J. W. 2014. Research Design: fourth edition. California: Sage Publication

Cutting, J. 2002.Pragmatics and Discourse. London: Routledge

Griffiths, P. 2006. An Introduction to English Semantics and Pragmatics. Edinburgh: Edinburgh University Press.

Horn, L. R. And Warn, G. 2006. The Handbook of Pragmatics. Oxford: Blackwell Publishing

Mey, J. L. 2009. Concise Encyclopedia of Pragmatics. Oxford: Elsevier Ltd.

Taher, A. 2015. “ApakahHewanBerbahasaSepertiManusia?” Retrieved July 15, 2017, from http://www.kompasiana.com/arditaher/apakah-hewanberbahasa-seperti-manusia_55d55d28cb23bd2707381053

Thor Subtitle. Retrieved September 27, 2016, from https://subscene.com/subtitles/thor/english/1445954

Thor Script. Retrieved September 8, 2016, from http://www.imsdb.com/scripts/Thor.html

Yule, G. 1996. Pragmatics. New York: Oxford university press

Yule, G. 2010. The Study of Language.Fourth Edition. New York: Cambridge University Press. 